\title{
Robotics Focused Capstone Senior Design Course
}

Fernando Rios-Gutierrez, Georgia Southern University, USA

Rocio Alba-Flores, Georgia Southern University, USA

\begin{abstract}
This work describes the educational experiences gained teaching the Senior Design I \& II courses, a senior level, twosemester sequence in the Electrical Engineering (EE) program at Georgia Southern University (GSU). In particular, the authors present their experiences in using robotics as the main area to develop the capstone senior design, with focus in interdisciplinary interactions and teamwork for the design and implementation of autonomous mobile robots. Other main purpose of the capstone design course sequence is for the students to experience working in an engineering application project researching and analyzing the sustainability, ethical and social impact issues related to their projects. The students work for two semesters as a team to design, test and build a mobile robot project for a particular application. Some of these projects have been fabricated to participate in different robotic competitions, including the IEEE sponsored hardware competition, the lawn mower competition, and the robot waiter competition.
\end{abstract}

Keywords: Capstone Design; Mobile Robots; Team Work; Robotic Competitions

\section{INTRODUCTION}

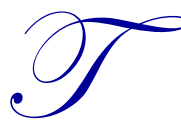

he number of automatic control and autonomous operation systems used in home and industrial applications continues to increase dramatically. These systems typically include many subsystems with separate processors or controllers. The processors must communicate to coordinate their activities. For example, a typical autonomous navigation system consists of an interconnected collection of processors linked to a real-time controller. As these systems become even more complex, the need for teamwork becomes even more critical.

A mobile robot is a system that contains a combination of mechanical and electronic parts that can be programmed to perform some specific functions, responding to sensory inputs under the control of an internal or external controller. The reasons to use mobile robots as the main topic for the Senior Design course is that in addition to involving the electrical and mechanical engineering disciplines, robotics deals with programming and artificial intelligence applications, as well as other sciences and humanities subjects, such as animal and human behavior imitation, learning techniques, and environment interactions. Robotic systems can relate to most processes in nature and human behavior. Because of this, their potential as educational tools for teaching and learning various subjects in engineering and sciences is unlimited as described by Khoukhi (2012), Bailey (2007), Nielsen (2004), Dutson (1997), Wessels (1995), Koen (1994), and Todd (1995).

The design and implementation of an autonomous mobile robot requires a broad knowledge in areas that are not covered by a single engineering discipline, as it is widely explained by Bailey (2006), Ernst (2006), Hanlon (2004), and Dixon (2002). These areas include electrical, mechanical and computer engineering, computing sciences, and other engineering disciplines. As a result, it is very difficult to train students and engineers within a single discipline to effectively design and implement a complex mobile robot. Thus, we felt that it was important to offer a senior design course to establish an interdisciplinary framework to teach the basics and offer a structured course for education in mobile robot design. Another important goal of this sequence of courses (Senior Design I and II) is to expose students to industrial and commercial quality design, learn about sustainability related to engineering, investigate the possible ethical and social issues related to their projects and bridge the gap between conceptual understanding and concrete implementations. 
As described by Lauren (2010), Schaefera (2009), Villarejo (2008), Russell (2007), Seymour (2004), and Dahm (2003), after undergraduate students are able to apply abstract knowledge in concrete implementations, other higher-level, theory-oriented courses have more relevance.

Some of the students doing the senior design sequence had experience participating in undergraduate research projects or industry internships, because of their experience, these students were viewed as better qualified to take charge of implementing the more complex parts of the projects or as best candidates to be team leaders for the different projects.

The next sections of this work are organized as follows. Section 2 presents the motivation and background. Sections $3 \& 4$ describes the senior design organization and the educational objectives respectively. Sections $5 \& 6$ describes the project administration and assessment for the courses respectively. Section 7 describes technical details of some of the robotic projects implemented as part of the senior design course. Section 8 presents the conclusion and recommendations for future work.

\section{MOTIVATIONS AND BACKGROUND}

Traditional approaches to system design in engineering disciplines have focused primarily on hardware design, whereas computing sciences have focused primarily on software design. With the introduction of robotic systems, it became possible to provide students with hands-on laboratory experiences to construct interdisciplinary and more complex systems. As robotic systems have evolved in research and commercial applications, the number and complexity of these systems have also increased. A significant portion of the design process must now focus on the integration of hardware and software. However, most senior design courses still emphasize just on the software writing or the hardware construction parts. In order to address both software and hardware issues, it becomes essential to apply a team-based approach.

Applications of robotic systems usually involve various types of sensors and actuators connected to a real-time controller. The complexity of these applications requires in-depth knowledge to correctly interface multiple sensors and actuators. These applications serve as excellent case studies to motivate students and teachers. Also, fast computation speed is a major barrier for many real-time sensing and control applications, especially for sensors requesting a large amount of computation, such as lasers, LIDARs, and image capturing devices. A real-time controller is important in applications where multiple subsystems are developed, each containing a large number of sensors and actuators. Modern robotic systems are equipped with advanced microprocessor-based embedded systems. For example, an autonomous vehicle may use several electronic control units and numerous sensors and actuators to monitor and improve its performance. With the rapid development of new technologies for precision navigation, more sensors and actuators with sophisticated control algorithms are added to the system. This requires more complex and reliable communications techniques. Many of these sensors may be linked with a real-time network to log sensory data and provide feedback for real-time control.

Robotic systems that are designed for real-time applications such as autonomous navigation systems are very expensive to develop. To be practical for a senior design project, the per-unit cost must be strictly controlled to fit within a typically constrained laboratory budget, since the cost of development of a platform for a mobile robot can become fairly expensive as the complexity of the sensors and control system are increased, it can reach thousands of dollars. In our case, we had to keep the cost of the robotic projects within the limits of the budget assigned to this class. To reduce the implementation costs, students had to design their systems using as many devices and components that were already available in our labs, such as sensors, electronic components, laptops, microcontroller cards, web cameras, and software tools.

In these projects, students integrated a sensor-information processing program into a real-time control system in order to accomplish the required navigation control of the robot. The sensor-information processing program developed for the projects was able of processing the data received from different sensors located in multiple locations of the mobile robot. In order to accomplish more complex navigation tasks, one of the robots developed in the course, included a fusion sensor algorithm which integrated the input of the laser and ultrasonic sensors with real-time positioning signals received from a Global Position System (GPS). Such systems can be used for many real-time field applications, including yield mapping, and programmed navigation. Also, in our case, all sensors, controllers, and actuators were 
networked together using a real-time master controller connected to multiple smaller controllers used to implement specific systems or handling sensor inputs.

\section{SENIOR DESIGN ORGANIZATION AND TEAMS INTERACTIONS}

The typical senior design class consists of a group of 15-25 students that are organized into independent design teams ( 2 to 3 students per team). At the beginning of Senior Design I, the faculty advisors together with the students in the class identify and select what robotic challenges will be implemented as part of their capstone project. Typically the advisors encourage the class to develop robotic systems that will be able to compete in one of the robotic competitions that will take place by the end of Senior Design II. The most common robotic competition that our students have participated in the last few years include the IEEE sponsored hardware competition, the Institute of Navigation Lawn Mower competition, and Trinity College's Firefighting and Robot Waiter competitions. Depending on the complexity of the challenges involved for the selected competition, one, two or three teams are assigned to develop a particular robotic project. The membership selection to a particular team and to a project is based on individual skills and personal preferences of the students. In case of conflicts the faculty advisors have the final decision on team's formation.

The design teams receive supervision from two faculty advisors. In general, one advisor is in charge of supervising the design of the base, the power system, and the motor control. The second advisor supervises the design of interfaces for the different sensors, the navigation method, and techniques to process data from advanced sensors such as GPS and video cameras. Figure 1 is a general block diagram that shows the interconnection of the different modules that can be used to implement an autonomous vehicle (mobile robot).

Figure 1. General Block Diagram of an Autonomous Vehicle

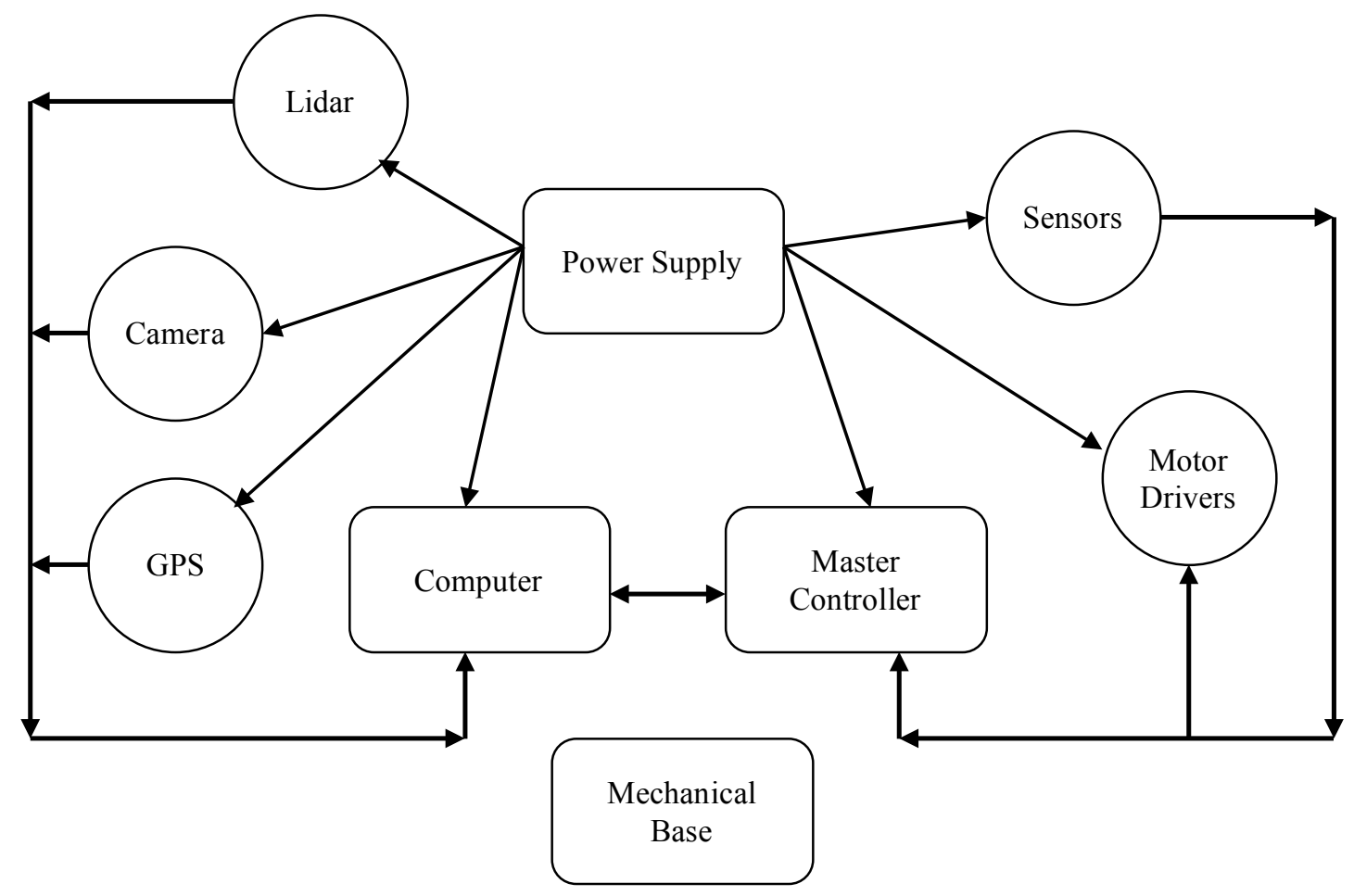

Each design team had a team leader. The team leaders were selected based on their leadership experience or managerial skills. Because some robotic projects were comprised of more than one design team, it was necessary to have an executive leader for these projects. The executive leader was selected among the design team leaders. The executive leader was the main communication channel between the students and the faculty members supervising the course. 
Each team was responsible for the implementation of one or more modules (depending on their complexity) for the autonomous vehicle project. Examples of some assigned design modules are as follows.

Team 1: Design and implement a mechanical base that includes: mechanical base, wheels, motors, motor drivers and other components to ensure that the vehicle is capable of performing the desired tasks.

Team 2: Design and implement the obstacle detection module that include ultrasonic sensors, camera, Lidar sensor, and algorithms to provide environment information for the autonomous vehicle.

Team 3: Design and implement the navigation program that is in charge of combining the data provided by the sensors, camera and GPS to control the navigation of the vehicle with the given data. Various algorithms were implemented in C-language and Matlab to control the vehicle.

The implementation of the projects for the senior design sequence is organized as a two-semester, 30 -week long project. The faculty members had weekly meetings with the students. In the first weeks (1-5) of the first semester, students receive 2-hour lectures related to the theoretical background needed for the design of the different components, an introduction to project management techniques, as well as the role of engineering in society, taking into account environmental, economic, and ethical issues. During the rest of the first semester students dedicate full time to do research, design and simulations of their projects. In the second semester, students dedicate full time to the development of their project and integrating the different modules and complete the robotic project. By week 5 of the second semester each team presents preliminary oral and written reports in which they describe the advances and problems they had in developing the projects. Weeks 6-13 were dedicated to integrate all modules and perform the debugging, testing, interconnecting and final assembly of the autonomous vehicles. In week 15, final oral and written reports of the completed vehicles are presented. For the teams that participated in competitions, the deadline to have a completed and working robotic vehicle was by the day of the competition that in most of the cases takes place during weeks $11-13$ of the second semester.

\section{SENIOR DESIGN EDUCATIONAL OBJECTIVES}

The outcomes of this course fulfills the departmental and ABET's requirement for a capstone senior design project, by providing a two-semester time period to complete the senior design project, and assure that students complete the projects on time, presenting professional written reports, professional oral presentations, and detailed analysis of engineering ethics, environmental impact, and sustainability aspects of their specific project. The instructors devote their effort to ensure that the assigned projects include application of knowledge acquired by the students in the EE curricula. In particular many projects include topics that students learned in digital system design, circuit analysis, signal processing, power systems, microcontrollers, and control systems. Based on ABET's educational outcomes, upon completion of the senior design course sequence students were able to:

a) Complete a design project that is interdisciplinary in nature, integrating the knowledge obtained in the EE program

b) Accurate communicate his/her project results, both in written report format and in oral presentation format

c) Understand how teams work and how to interact in a team setting. (Understand what is like to work in industry).

d) Appreciate the role of engineering in society, so that students take into account environmental, economic, social and ethical issues that are important in the development of an engineering project.

\section{PROJECT BUDGET AND ADMINISTRATION}

The budget assigned to each team in the senior design course was $\$ 200$. This is enough to cover the cost of the basic parts for each vehicle, but this does not include the costs of advanced sensors or parts that we already had available in the department such as the laptops, GPS units, cameras, sensors, LIDAR and software packages. Taking these components into account the actual cost increases to about $\$ 3500$ for each vehicle. One faculty member was in charge of advising the students on administrating the budget. The main challenge in managing the budget was to find the appropriate parts to be used in the project that were in the price range that they could afford. 


\section{CAPSTONE PROJECT ASSESSMENT}

The projects were evaluated in several stages, in a gradual and continuous way. In weekly meetings, each team meets with the faculty advisor to present a weekly log of the activities and discuss the evolution of their projects and receive guidance from the faculty advisor. Another reason to have the weekly meetings is also to have a close observation of the teams' interactions and to assure that each team member contributed to the teamwork. During the ninth week of each semester, $30 \%$ of the final grade is assigned, after the students presented the preliminary written report and oral presentation of the results in their progress. Another $30 \%$ of the final grade is assigned based on the end of the semester oral presentations and written reports. Specific rubrics for oral presentation and written reports are used to assess the quality and clarity of the presentation, and the quality and completeness of the final written report. The last $40 \%$ of the final grade is assigned to the students during the last week of the semester when they demonstrate that their projects worked in accordance to the proposed specifications. As a motivation, for teams to participate in robotic competitions, the electrical engineering department covers their travel expenses, and issues certificates of participation to each team member that can be used for curriculum enhancement.

To assess the outcome related to the role of engineering in society, each team is evaluated by taking into account environmental, economic, social and ethical issue related to their projects. During the first semester (Senior Design I) the instructor dedicated three lecture hours to discuss topics related to engineering professionalism, engineering ethics, environmental impact and sustainability. Engineering ethic cases are analyzed and discussed in class teams are encouraged to identify conflicts and propose possible solutions. Also oral presentations dedicated specifically to address the ethical, economic, environmental, and sustainability aspects of each particular project were presented in the middle of the first semester (Senior Design I). A rubric was provided to the students as a guide to prepare their oral presentations on those topics. In the second semester (Senior Design II), as part of the final written technical report, students included a chapter addressing engineering professionalism, engineering ethics, the environmental impact and the sustainability aspects in their specific project. Also a rubric was provided to the students as a guide to prepare that particular chapter.

\section{AUTONOMOUS VEHICLE DESIGN AND IMPLEMENTATION}

In this section, as an example, one of the senior projects is explained in detail: the Autonomous Lawn Mower project (fig. 2). This is a typical mobile robot project that shares many of its main components with other mobile robots applications that have been designed and built as part of our senior design course. Therefore all this section is dedicated to explain the specifics of the Autonomous Lawn Mower project. For this robot, all the electronic components, except the sensors, camera, GPS, and gas engine, were mounted inside a protecting metallic box. This box provided the best noise and environmental protection to the computer and other sensitive electronic equipment. To make the electronic components weatherproof, all sensitive components were placed inside sealed plastic boxes, and then placed in the metallic box. The original frame of the lawn mower was modified so it could hold safely the metallic box as well as the sensors that were mounted outside the vehicle. The GPS antenna and an emergency stop button were mounted on top of the metallic box. The obstacle sensors were mounted pointing to the front and rear of the mower. A simple metallic frame was used to hold all the mechanical components, gas engine and mowing deck. 
Figure 2. The Autonomous Lawn Mower Project

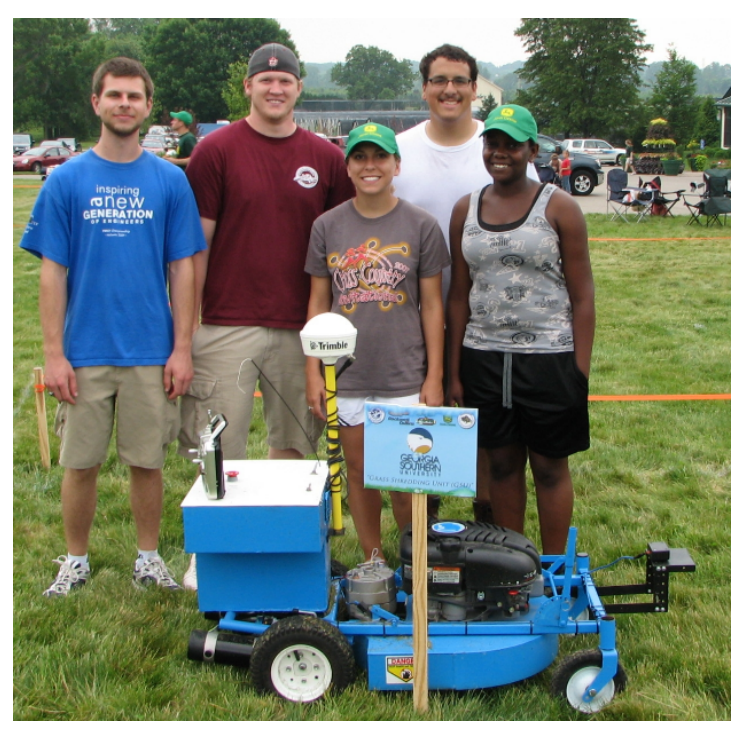

Due to the frame's simple design, reinforcing studs were placed along the runners which aid in supporting the weight placed in the middle of the vehicle. With these modifications the vehicle was able support roughly 200 lbs without showing any signs of stress, and was very stable during turns. However the overall weight was not enough for the tires to provide traction on soft surfaces. Unfortunately the tires did not provide good enough traction in grass or gravel, so golf spikes were inserted into the rear tires. With these changes the vehicle had better traction on most surfaces.

Motors and Motor Control: The majority of the robots implemented in the senior design course use DC motors to drive the wheels, which are controlled independently in speed and direction. The driving wheels implement a differential drive system used for controlling the direction of movement. The direction of rotation and speed of the motors are controlled by two digital signals going into an H-Bridge. One control signal is used to regulate the speed of the motors using a pulse width modulation waveform that is provided from one of the microcontroller ports. The second digital signal is a direction signal used to control the direction of rotation for the motor, either forward or reverse.

Steering System: An important action of the steering control is to make sure that the vehicle is heading in the correct direction. In order to check this parameter, a digital compass was added to verify the steering. If the vehicle is not turning and veers slightly off the desired heading, the controller tells the steering drive to turn in order to put the vehicle in the correct heading. The main purpose of the digital compass is to detect the direction that the vehicle is currently moving. The compass used must be calibrated to the magnetic north, so data obtained from the compass is correct.

The main information for controlling the robot's navigation is obtained from the compass and GPS. A laptop computer takes data from these devices and sends corresponding navigation control signals to the motors' controllers. So, the laptop analyzes the data and tells the vehicle to go straight, turn the wheels to the left, or to the right, etc. The navigation algorithm says how much to turn or advance from the current heading. From this value, the controller calculates the desired heading by adding the turn angle to the current heading. Also, the turn angle indicates what direction the wheels need to turn.

Wireless RC Drive, Remote Kill and Emergency Stop: The autonomous mower is heavy, so a wireless remote control (RC) driving system was added to control it manually when needed. A wireless controller was stripped out of a toy RC car. The vehicle's power system has a latching relay which takes a pulse to stop and disconnect the power to the driving motors in case of an emergency. Since the robot will never be driven wirelessly and remote killed at the same time, it was decided to use the same circuit for both purposes. An industrial emergency stop button was 
added to the robot. The button is a push to break style button. Pushing down the button cuts power to the drive motors and instantly stops the robot.

The Power Supply Module: Since the different electrical components of the vehicle have specific voltages, currents and power requirements, a power supply module was constructed to provide all power requirements. The main power input came from a pair of 12-volt batteries connected in parallel. The H-bridges that drive the DC motors required 12 volts, the microcontroller board and sensors required 5 volts, and the GPS required $5 \& 3$ volts. The video camera and the laptop were powered using their own batteries. The Power Supply Module also receives an emergency disconnect control signal from the main emergency stop button.

Connection between Microcontroller and Computer: The connection between the microcontroller (an Arduino development board), and the laptop computer was implemented using the computer's USB port. The USB port was connected to an USB shield for the Arduino using ribbon cable. In Matlab, the Data Acquisition Toolbox gives the user the ability to communicate with the USB port. By connecting the computer to the microcontroller, the navigation algorithm can use the data that comes in from the sensors and the compass to help control the steering of the vehicle.

\section{Navigation Controller.}

The navigation controller is the brain of the autonomous vehicle; it takes inputs from the ultrasonic sensors, video camera, compass and GPS in order to decide the movements of the vehicle. Next we give a description of the operation of this system.

Ultrasonic Sensors: The purpose of the ultrasonic sensors is to gain information about how close a physical object is from the vehicle. Also, by using multiple sensors and the parallax method (Steiman, 2000), it is possible to determine how far an object is from the center of the robot. It was determined that three sensors in the front and one in the rear of the vehicle will be sufficient to help in the control of the navigation. Three ultrasonic sensors (SR 04), located on the front are the main source for detecting the location of close physical obstacles. In arranging the front sensors like this, the desire was to gain information not only about how far away each obstacle is, but also an approximation on the location of each obstacle. The first way this is accomplished is if there is an object detected on one or two of the sensors and not on the other(s). For example, if an object is detected on the left and center sensors, but not on the right, then the object is located to the left of the center of the vehicle. This system uses the parallax method to find the approximate location of the objects. This is show in Figure 3. If an object is detected on all three sensors, the distances to the edge sensors will be compared. By using simple trigonometric properties, the horizontal offset from the center of the vehicle is obtained. If the vehicle ever needs to backtrack, the rear sensor, which is located on the center of the rear bumper, will give useful information about distances to objects located behind it.

Sensor Data and Processing: Using Matlab, students were able to implement an ultrasonic sensor's "image" processing algorithm to determine the presence of obstacles in front of the robot. First, the program calls a simple I/O command that captures a frame of data from all the sensors to have it available for manipulation. Next, the data is processed to find out which sensors are detecting obstacles. The next step is to collect the information provided by the compass and ultrasonic sensors to generate the correct speed and direction commands to the motors. The navigation algorithm looks at the data given to the controller by the various components to determine in which direction to move. The main components used to navigate the vehicle are the GPS, the compass, and ultrasonic sensors which information is used to help in the control of the navigation. The navigation algorithm first obtains the data from all devices. The algorithm then looks forward to see if the area is clear. The vehicle is 32 " wide, so it needs to be an area that is big enough for the vehicle to pass through. 
Figure 3. Distance measurement using ultrasonic sensors

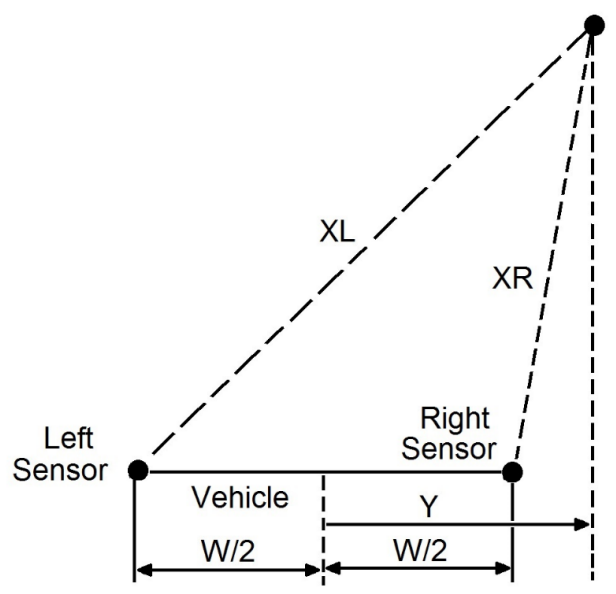

Navigation Control: The autonomous lawn mower main navigation control input consist of a series of waypoints that indicate the area to mow. This means that a set of desired waypoints are entered to the robot, so that the robot can visit each way point in the indicated sequence using only GPS data. Depending on the geometric shape of the area that will be mowed, between 4 to 10 waypoints are given to the robot. A Garmin differential unit was used to obtain the GPS data, then the navigation algorithm obtains the desired angle the vehicle needs to travel in to get to the desired waypoint. Using this angle as a desired heading, the navigation algorithm determines what angle the vehicle needs to turn to get at the desired angle according to the GPS. If the path is clear, the vehicle turns at that angle. If the path is not clear, the navigation algorithm looks for the closest angle that gives a clear path. Once that angle is found, the vehicle turns at that angle. While the vehicle is turning, the algorithm is checking the sensors and camera to see if there are any objects in the way. The algorithm also constantly checks the current GPS location to see if the vehicle is at the desired waypoint. If the current GPS location does match, the algorithm sets the desired location as the next waypoint.

Combining the various detection components into this navigation system provides the autonomous vehicle with the information needed to properly navigate through the unknown environment. The system will examine the data and come to an intelligent decision of which direction to take. Once all components of the vehicle have been installed and are working individually, they must all be integrated into a single system that will control the overall operation of the vehicle. The navigation control program is written in Matlab and uses the information provided by each input to determine the autonomous vehicle's direction.

The Global Positioning System (GPS) is a satellite-based navigation system made up of a network of 24 satellites placed into orbit by the U.S. Department of Defense. The accuracy of new handheld GPS receivers without a differential correction is about 15 meters on average. The error is due to a combination of several factors including: orbital errors, satellite clock errors, errors in the speed of the signal through the ionosphere and the troposphere, receiver noise, and multipath errors. This gives the receiver an erroneously long time measurement. One way to correct or eliminate some of these errors is to use what is called the Wide Area Augmentation System (WAAS) (FAA, 2006). It uses 25 ground based stations positioned in the United States to monitor errors in satellite orbit, clock drift, and signal delays caused by the atmosphere and ionosphere. GPS receivers that use WAAS correction can obtain an accuracy of less than 3 meters, $95 \%$ of the time.

A software interface implemented in Matlab, is used to control the communication between the PC and the GPS unit and to process the received data. The GPS program developed also implements a function to convert latitude and longitude to Universal Transverse Mercator (UTM). This allows the navigation program to work with distances and directions in X-Y coordinates. The UTM system applies the Mercator projection to mapping the Earth. The map provides low distortion at points near the tangent meridian (also called the central meridian). Choosing points farther away from the central meridian will result in higher distortion. To provide a low distortion map of the whole Earth, 
the UTM defines 60 different standard projections. Each projection is centered on a meridian that is 6 degrees from the next central meridian. The projections are called UTM zones.

In the last 10 years, senior projects have included the design and implementation of robots that have competed at the SouthEastCon Hardware Competition that takes place every year as part of the IEEE Region 3 SouthEast Conference. Figure 4 and 5 show two of the robots that have participated at SouthEastCon. Figure 6 shows a GPS Navigation Controlled Robot.

Figure 4. The SoutheastCon 2013 Robot

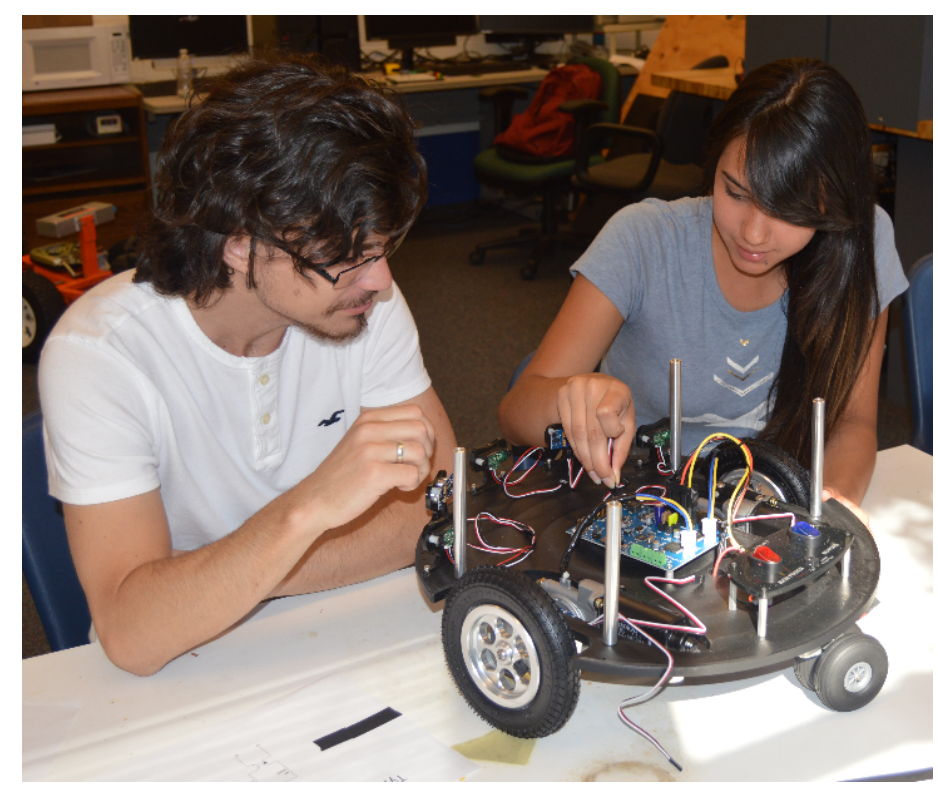

Figure 5. The SoutheastCon 2016 Robotic Competition

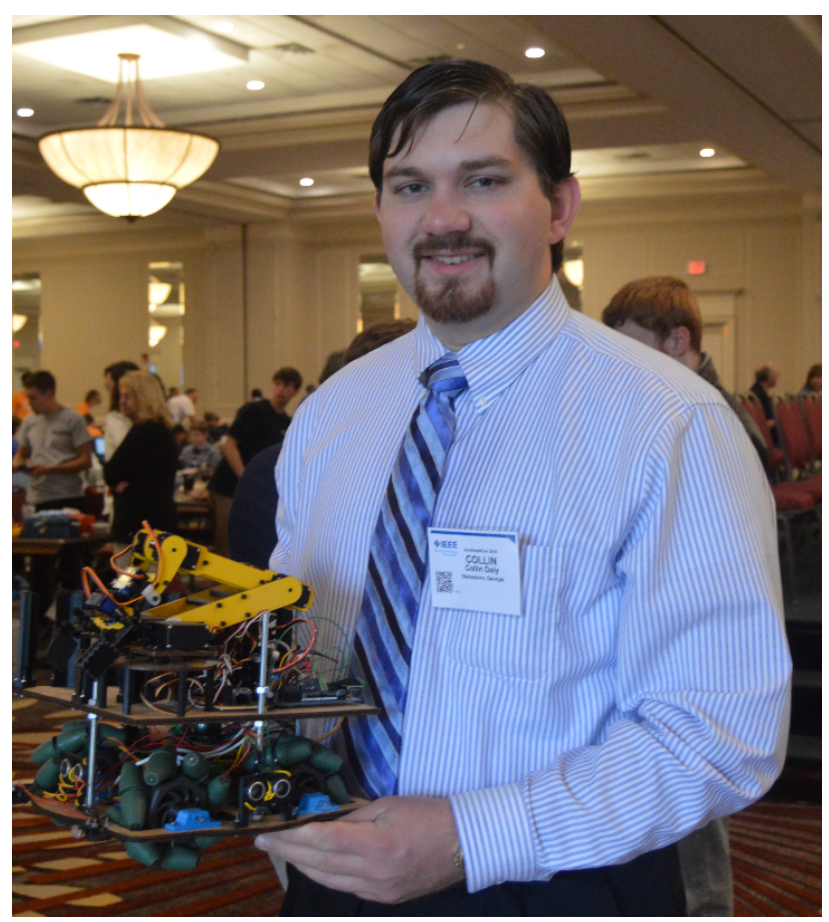


Figure 6. A GPS Navigation Controlled Robot

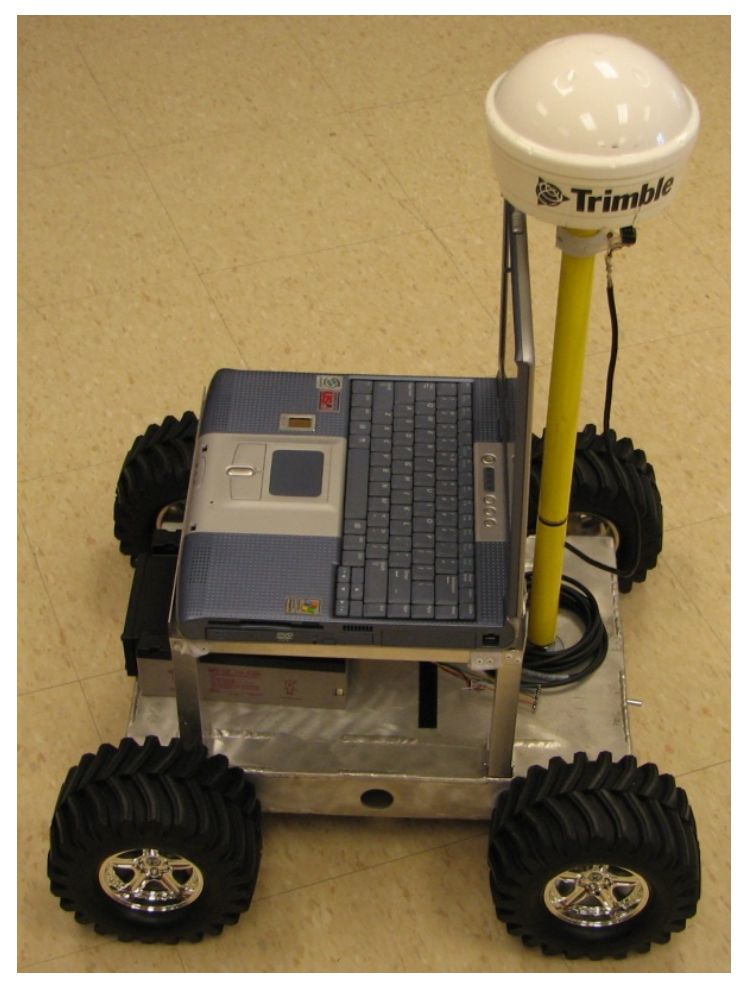

\section{CONCLUSIONS}

Several autonomous vehicles were designed and built for the specific task of participating in the different robotic competitions, and to fulfill the senior design requirement for the students in our department. The participation in these projects gave students a real life team work experience. Also, they experienced the application of theoretical knowledge in different areas of knowledge to solve real life problems. This experience could later be used in their professional careers to solve similar problems in numerous other applications. The potential of real-world autonomous devices being able to control themselves is growing, and in some cases is very desirable. Throughout the process of designing and building the autonomous vehicles, the teams encountered many problems and made some mistakes of their own and they had to be realized and acted on accordingly. The top challenge for students and faculty members was to manage the schedule for each team, so that they were all ready to be put together by the end of the tenth week. It would be more desirable to have more time to construct the vehicles. Based on the time constraints that many of our teams have had, along with a limited budget, the final result that our teams have obtained have been better than expected. Overall, these type of senior design projects have been able to integrated a variety of electrical, computer, and mechanical engineering techniques, along with computer science and mathematics. These experiences have also provided the students with a way to transfer theoretical knowledge into a practical application, being an invaluable final step in the electrical engineering program.

\section{AUTHOR BIOGRAPHIES}

Fernando Rios-Gutierrez is an Associate Professor in Electrical Engineering at Georgia Southern University. He received a Ph.D. degree in electrical engineering from Tulane University (New Orleans, Louisiana) in 2000. He had held teaching and research positions at the Autonomous University of Puebla (Mexico), the University of Las Americas (Mexico), University of Minnesota Duluth, and Georgia Southern University. Dr. Rios's research includes Robotics, Embedded Systems, and Artificial Intelligence application techniques to control. Dr. Rios is a member of IEEE from which he received the Outstanding Educator Award in 2013. E-mail: frios@georgiasouthern.edu 
Rocio Alba-Flores is an Associate Professor in Electrical Engineering at Georgia Southern University. She received a Ph.D. degree in electrical engineering from Tulane University (New Orleans, Louisiana) in 1999. She had held teaching and research positions first at Trinity College (Hartford, CT) and later at Alfred University (Alfred, NY), before joining Georgia Southern University in 2008. Dr. Alba's research includes Control, Robotics, and Artificial Neural Networks applications. Dr. Alba is a member of the IEEE, and an ABET evaluator for engineering programs. Email: ralba@georgiasouthern.edu

\section{REFERENCES}

Bailey, R. \& Szabo, Z. (2006). Assessing engineering design process knowledge. International Journal of Engineering Education, 22(3), 508-518.

Bailey, R. (2007). Effects of Industrial Experience and Coursework during Sophomore and Junior Years on Student Learning of Engineering Design. Journal of Mechanical Design, 129(7), 662-667. doi:10.1115/1.2722323

Dixon, M. W. (2002). Alternatives for Establishing Effective Capstone Design Teams. Proceedings of the American Society for Engineering Education Annual Conference \& Exposition, Montreal, Canada.

Ernst, N., Brickley, S., Bailey, R., \& Cornia J. (2006). Effects of First-Year Engineering Design Course Models on Student Design Process Knowledge. Proceedings of the Frontiers in Education Conference, San Diego, CA. doi: 10.1109/FIE.2006.322425

Dahm, K. D., Newell, J. A., \& Newell, H.L. (2003). Rubric Development for Assessment of Undergraduate Research: Evaluating Multidisciplinary Team Projects. Proceedings of the American Society for Engineering Annual Conference \& Exposition, Nashville, TN.

Dutson, A., R. Todd, S. P. Magleby, \& Sorensen, C. D. (1997). A Review of Literature on Teaching Design Through ProjectOriented Capstone Courses. Journal of Engineering Education, 86(1), pp. 17-28.

FAA/Williams J. Hughes Technical Center (2006), Wide-area Augmentation System Performance Analysis Report, Federal Aviation Administration, Report 17, July 2006.

Hanlon, P. D., Goda, B. S., \& Shay, L. A. (2004). Experience with Multidisciplinary Design Projects at the US Military Academy. Proceedings of the American Society for Engineering Annual Conference \& Exposition, Salt Lake City, UT. https://peer.asee.org/13898

Khoukhi A. (2012). A Structured Approach to Honors Undergraduate Research Course, Evaluation Rubrics and Assessment. Journal of Science Education and Technology, 22(5). DOI: 10.1007/s010956-012-9419-3

Koen, B. V. (1994). Toward a Strategy for Teaching Engineering Design, Journal of Engineering Education, 83(3), pp. $193-201$. doi: 10.1002/j.2168-9830.1994.tb01104.x

Laursen, S., Hunter, A., Seymour, E., Thiry, H., \& Melton, G. (2010). Undergraduate Research in the Science, Engaging Students in Real Science, John Wiley \& Sons.

Neilsen, M., Lenhert, D., Mizuno, M., Singh, G., Staver, J., Zhang, N., Kramer, K., Rust, W., Stoll, Q., \& Uddin, M. (2004). Encouraging Interest in Engineering through Embedded System Design. Proceedings of the American Society for Engineering Annual Conference \& Exposition, Salt Lake City, UT. https://peer.asee.org/12861

Russell, S. H., Hancock, M. P., \& McCullough, J. (2007). Benefits of Undergraduate Research Experiences. Science (Washington), 316(5824), 548-549.

Seymour, E., Hunter, A-B., Laursen, S. L., \& DeAntoni, T. (2004). Establishing the benefits of research experiences for undergraduates in the sciences: First findings from a three-year study. Science in Education, 88(4), 493-534.

Schaefera, D. \& Panchalb, J. H. (2009). Incorporating research into undergraduate design courses: a patent-centered approach. International Journal of Mechanical Engineering Education, 37(2), 98-110.

Steinman, S. B., Steinman, B. A., \& Garzia, R. P. (2000). Foundations of Binocular Vision: A Clinical perspective (pp.2-6). McGraw-Hill.

Todd, R. H, Magleby, S. P., Sorenson, C. D., Swan, B. R., \& Anthony, D. K. (1995). A Survey of Capstone Engineering Courses in North America. Journal of Engineering Education, 84(2), 165-174.

Villarejo, M., Barlow, A. E. J., Kogan, D., Veazey, B. D., \& Sweeney, J. K. (2008). Encouraging Minority Undergraduates to Choose Science Careers: Career Paths Survey Results. CBE Life Sci. Education, 7(4), 394-409. doi: 10.1187/cbe.08-040018

Wessels, W. \& Pumphrey, G. (1995). The Effects of Cooperative Education on Job Search Time, Quality of Job Placement and Advancement. Journal of Cooperative Education, 31(1), pp. 42-52. 


\section{NOTES}

